Connotas. Revista de crítica y teoría literarias 
CONNOTAS. REVISTA DE CRÍTICA Y TEORÍA LITERARIAS. Enero - diciembre 2013, es una publicación anual editada por la Universidad de Sonora, a través de la División de Humanidades y Bellas Artes, en el Departamento de Letras y Lingüística. Blvd. Luis Encinas y Blvd. Rosales s/n, Col. Centro, C.P. 83000, Hermosillo Sonora; Tel. (662) 2592 136, (662) 2592 157, <www.uson.mx>, <http://www.connotas.uson.mx, connotas@capomo.uson.mx>. Editor responsable: Rosario Fortino Corral Rodríguez. Reservas de Derechos al Uso Exclusivo núm. 04-2006-020714184900-102. ISSN: 18706630; ambos otorgados por el Instituto Nacional del Derecho de Autor. Licitud de Título núm. 13434 y de Contenido núm. 11007, otorgados por la Comisión Calificadora de Publicaciones y Revistas Ilustradas de la Secretaría de Gobernación. Este libro se publicó con el apoyo del Programa Integral de Fortalecimiento Institucional C/PIFI 2013-12934

Se autoriza la reproducción total o parcial de los contenidos de la presente publicación, siempre y cuando se acredite adecuadamente el origen de los mismos.

Datos de contacto para la publicación: División de Humanidades y Bellas Artes, Departamento de Letras y Lingüística; Apartado Postal 793, Col. Centro, C.P. 83000, Hermosillo, Sonora, México. Tels.: (662) 259-21-87, Tel-fax 212-55-29. Correo electrónico: connotas@capomo.uson.mx Página web: http://www.connotas.uson.mx 


\section{Connotas. Revista de crítica y teoría literarias}

Núm. 13, año 2013

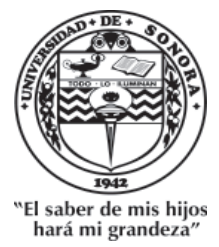


UNIVERSIDAD DE SONORA

RECTOR

Heriberto Grijalva Monteverde

VICERRECTORA

Arminda Guadalupe García de León Peñúñuri

Secretario General Académico

Enrique Fernando Velázquez Contreras

División de Humanidades y Bellas Artes

María Rita Plancarte Martínez

Departamento de Letras y LingÜística

Ana Bertha de la Vara Estrada

César Avilés Icedo

Rosa María Burrola Encinas

Fortino Corral Rodríguez

Leticia Martínez Figueroa

Jesús Abad Navarro Gálvez

Gabriel Osuna Osuna

María Rita Plancarte Martínez

DiRECTOR

Fortino Corral Rodríguez

Giuseppe Bellini

Consejo InTERnacional

Universidad de Milán

Carlos Pacheco

Luis Beltrán Almería

Universidad Simón Bolivar

Universidad de Zaragoza

Rafael Olea Franco

Helena Beristáin

El Colegio de México

Joan Oleza Simó

Universidad Nacional Autónoma de México

Universidad de Valencia

Raúl Bueno-Chávez

Dartmouth College

Julio Ortega

Evodio Escalante

Brown University

Luz Aurora Pimentel

Universidad Autónoma Metropolitana

Universidad Nacional Autónoma de México

Beatriz González-Stephan

Susana Reisz

Rice University

Aníbal González

The City University of New York.

José Carlos Rovira

Universidad de Alicante

Yale University

Aurelio González Pérez

Charles Tatum

El Colegio de México

Yvette Jiménez de Báez

The University of Arizona

Jorge Urrutia

El Colegio de México

Universidad Carlos III de Madrid

Nelson Osorio Tejeda

Universidad de Santiago de Chile

Emil Volek

Arizona State University 


\section{Índice}

\section{Artículos}

Una hermenéutica analógica para la literatura

Mauricio Beuchot Puente

La obra de Jorge Luis Borges durante la década de 1930: estudio de algunos elementos para la conformación de su poética en Discusión (1932)

Daniel Zavala Medina

Metáforas de la locura y la muerte en "Río subterráneo" de Inés Arredondo

Gabriel Osuna Osuna

La alteridad como vector de la construcción del yo: La muerte me da de Cristina Rivera Garza y El Gran Vidrio de Mario Bellatin Véronique Pitois Pallares

Uno soñaba que era rey de Enrique Serna: un espacio de contradicción Claudia Gidi

Una angustia compartida. Análisis de la voz narrativa en Mi hermano Carlos de Jorge López Páez

Jorge Antonio Muñoz Figueroa

De Los perros románticos y otros poemas de Roberto Bolaño Marina Martínez Andrade 
Las novelas del Crack, multiplicidad y superposición de mundos Ramón Alvarado Ruiz

La construcción del “otro" en la Relación de la jornada de Cíbola de Pedro Castañeda de Nájera

Guillermo Martínez Sotelo

Destino e historia en Margarita, está linda la mar de Sergio Ramírez

María Rita Plancarte Martínez

\section{Notas}

Identidad negada y mundo al revés en Santa María del Circo de David Toscana

César Avilés Icedo y María Elena González Borgaro 203

"El buen ejemplo" de Vicente Riva Palacio: la historia de un cuento

Marco Antonio Chavarín González

Organización descriptiva en Catarina de San Juan, princesa de la India y visionaria de Puebla

Silvia Guadalupe Alarcón Sánchez

Genealogías en Todo aqui es polvo de Esther Seligson. Lectura a partir de los epígrafes

Luz Elena Zamudio Rodríguez

\section{Reseñas}

Martha Elena Munguía Zatarain. La risa en la literatura mexicana (apuntes de poética)

Silvia Alicia Manzanilla Sosa 
Véronique Pitois-Pallares. El arte del fragmento: El Gran Vidrio de Mario Bellatin

Julio César Zárate Ramírez 255

Nicolás Kanellos. Hispanic Immigrant Literature: El sueño del retorno Josué Gutiérrez González

Dante Salgado. Brevísima relación de la idea de amor en Occidente Diana Vanessa Geraldo Camacho 271

Mara L. García. Paco Yunque: una mirada crítica Juan Paredes Carbonell 279

Abstracts 283

Résumés

Normas editoriales 



\title{
"El buen ejemplo" de Vicente Riva Palacio: la historia de un cuento
}

\author{
Marco Antonio Chavarín GonzÁlez*
}

Resumen:

De los veintiséis cuentos que Vicente Riva Palacio (1832-1896) incluyó en su último libro, Cuentos del General (1896), la mayoría ya se había publicado en algunos periódicos españoles y mexicanos (1892-1893). Pero quizá sólo uno, "El buen ejemplo", es rastreable hasta sus orígenes casi de anécdota -en Los ceros. Galería de Contemporáneos (1882) - al final de un "Cero" dedicado a Juan Antonio Mateos. En esta semblanza que combina magistralmente varios géneros literarios, entre ellos el ensayo, aparece la primera versión del cuento con al menos dos funciones muy claras, la ejemplificación y la matización-mediante el humorde las opiniones previamente vertidas. Sin este antecedente y otros, como la consideración de Quintiliano -al que Riva Palacio cita varias veces en la semblanza- y su comparación con el cuento ejemplar del xIx, sería incompleto el acceso a la versión definitiva. Propongo, por tanto, un análisis comparativo-descriptivo de las dos versiones del cuento.

Palabras clave:

Riva Palacio, Cuentos del General, El buen ejemplo, cuento del XIX, Los Ceros.

Según la mayoría de sus estudiosos, Vicente Riva Palacio publica Cuentos del general un poco antes de su muerte, acaecida el 22 de no-

* El Colegio de San Luis. 
viembre de 1896. En el volumen se incluyen, sin un orden aparente, la mayoría de los cuentos que ya habían aparecido entre 1892 y 1893 , en algunos diarios de Madrid y de la Ciudad de México; principalmente, en La Ilustración Española y Americana, El Partido Liberal, El Siglo Diecinueve y El Nacional. Debido a que el libro no tiene prólogo, no se sabe con certeza la razón por la que no incluyó algunos cuentos como "Amor correspondido", "El hermano Cirilo", "Los Azotes" y "Consultar con la almohada". Se ha sugerido que Riva Palacio, al sentirse enfermo durante 1896, dejó de participar en su edición, como lo había venido haciendo, y quiso que el libro se publicara cuanto antes, así cual había quedado, a medio terminar. Aunque la inclusión de un prólogo no sería garantía de nada, ya que la mayoría de los cuentos fue escrita en función de alguna idea particular y el volumen estructurado, al parecer, a partir de lo que se conoce como antología miscelánea; donde se incluye todo texto que vio la luz anteriormente en alguna sección de alguna publicación periódica.

En un intento por incluir elementos tan dispares en un solo listado, Clementina Díaz y de Ovando propone dividir el libro en cuentos "humorísticos, históricos, anecdóticos, fantásticos y de animales" (xlvi). Si bien esta clasificación tiene un claro problema, en cuanto a que cada rubro pertenece a ramas y niveles muy distintos, y es difícil hallar algún elemento más general que los subordine a sí y los integre entre ellos de manera coherente, ha sido repetida y repetida, como quizá ahora lo hago yo, por la mayoría de los estudiosos de la obra. Sin embargo, y esto sí hay que repetirlo, como la misma clasificación de Díaz y de Ovando lo demuestra, Cuentos del general es una antología de cuentos miscelánea. El volumen toma su título de la sección del mismo nombre en La Ilustración Española y Americana y no se sabe si fue nombrada por alguien del periódico o por el propio Riva Palacio. Sin embargo, hay que reconocer que parece una excelente estrategia de mercadotecnia para la prensa madrileña decimonónica, ofrecer la posibilidad de leer lo que tenía que decir un general mexicano que había peleado contra Maximiliano y hasta había recibido su caballo de regalo.

Pero vayamos a lo práctico. Lo que me interesa aquí, más que nada, es resaltar el origen de uno de los cuentos, "El buen ejemplo", 
es el que parece haber sido el primero en bosquejarse. Digo bosquejarse y no escribirse, porque la versión definitiva del mismo apareció hasta el primero de octubre de 1892 en el diario El Siglo Diecinueve, y Riva Palacio había empezado a publicar los cuentos de este periodo desde el 22 de septiembre de ese año en La Ilustración Española y Americana. Además, el cuento "Ciento por uno" había visto la luz desde el 15 de septiembre de 1887, también en el diario El Siglo Diecinueve (ver Díaz y de Ovando). Las ideas de algunos de sus textos pueden rastrearse en su obra anterior, como es el caso del cuento "El matrimonio desigual", que incluye pasajes del relato Cuentos de un loco (1874), y del cuento "El voto del soldado", que se refiere a un fragmento del viaje de Cortés a las Hibueras, incluido en su novela La vuelta de los muertos (1870).

Sin embargo, el año que considero más significativo, por lo menos para entender la poética del cuentario, es 1882, porque en ese año aparece lo que Díaz y de Ovando (1971) llama "Primera versión de El buen ejemplo"; es decir, Riva Palacio escribe el cuento, casi a nivel de anécdota y junto con otro cuentito de pericos que nunca desarrolla, para incluirlo como parte de un texto mayor, una especie de semblanza ensayo dedicada a su amigo Juan Antonio Mateos. Este texto se incluye en Los ceros: galería de contemporáneos, un libro que recopila la mayoría de estos escritos, a los que se llama ceros. Muchos de ellos fueron publicados durante los primeros meses de 1882 en el diario La República, por Riva Palacio, con el seudónimo de Cero. Llama la atención, además del excelente prólogo que se burla de los prólogos, que muchas de las semblanzas fueron matizadas, corregidas y ampliadas. Entre ellas, la dedicada a Justo Sierra y, por supuesto, la de Mateos. Otras, por el contrario, como las dos que se refieren a Gutiérrez Nájera -donde lo trata de plagiario y le critica hasta el peinado-, nunca fueron incluidas.

Revisemos, rápidamente, la semblanza de Mateos. Dos de los reproches que se hacen a Mateos, y que funcionan como las principales líneas temáticas del texto, son, en el aspecto literario, que escribe mucho y lee poco y, en el aspecto público, la dispersión de las ideas en sus discursos pronunciados en el Congreso. Respecto a que lee poco, el mismo Riva Palacio sirve de contraste, pues sus ceros se 
caracterizan por incluir una gran cantidad de citas -no hay que olvidar que por ello Alfonso Reyes (1955) lo acusa, a su vez, de incontinencia-. Los problemas de Mateos se deben, paradójicamente y según Cero, a la capacidad del escritor de El Cerro de las Campanas de aplicar su genio creativo a una gran variedad de actividades: "Juan Mateos se pone tan fácilmente a escribir una letrilla como a rumiar el discurso que pronunció en una discusión del presupuesto, como a preparar el argumento de un drama" (Riva Palacio Los ceros 233); por lo que profundiza poco en los temas que trata.

Riva Palacio también hace gala en este cero de un buen dominio de las reglas de oratoria propuestas por Quintiliano en sus Instituciones Oratorias, al señalar los distintos defectos que tenían los representantes populares de aquel entonces.

Yo he visto a un orador levantando las manos como para sostener la techumbre. (¿Quién no conoce a Guillermo Prieto?). A otro, osando apenas separarla de su pecho. (Aquí el Señor Bermúdez). Alargando otro el brazo en toda su longitud. (Aquí entra Dublan). Moviendo otro la mano como si tuviera un látigo. (No hay más que recordar al diputado Carvajal). Alguno afectando la postura de la estatua del Pacificador, inclina la cabeza sobre el hombro derecho, el brazo tendido a la altura de la oreja, la mano desplegada y el pulgar al aire. (Éste es un retrato de Justo Sierra). Algunos oradores meciéndose constantemente de un lado a otro como Curion, el padre, de quien Julio preguntó: “¿Quién es ese hombre que habla desde un buque?”. (Riva Palacio Los ceros 232)

Imita, mediante el pastiche, uno de los discursos de Mateos, poniendo en evidencia la mezcla caricaturesca que, según Riva Palacio, hace aquél en sus discursos:

Ciudadanos diputados:

Con las velas de mi bajel henchidas por el proceloso viento de la discusión, me arrojo entre las revueltas ondas de este debate, como las perdidas carabelas de Colón entre las nieblas del Atlántico. 
El Estado de Hidalgo lanza su cañonazo de socorro, y por eso, antiguo soldado de la Reforma, quiero hacer fuerza de debate antes de que la sombra pavorosa del bonete de los hijos de Loyola se proyecte como un recuerdo de Torquemada y Pedro de Arbués sobre los campos del Estado que vio brillar el sol de Culpulalpam.

Los buitres que se ciernen sobre la Constitución huirán a ocultarse medrosos bajo los mármoles del Vaticano, al primer estallido del rifle del progreso que suena como precursor del gemido de la locomotora.

¿Qué brille, ciudadanos diputados, la alta sabiduría de la Cámara, para apagar las antorchas sangrientas del fanatismo, arrancadas de la hoguera de Juan Huss y de Savonarola! (Los ceros 236)

Ante lo obvio, Cero arguye irónicamente que él no se atreve "a decir que Juan Mateos no sabe lo que dice, cuando dice todas estas cosas, porque me expondría yo a que dijeran de mí que hablo como un loro" (Los ceros 236). Así, da entrada a la primera anécdota de pericos, que Riva Palacio incluye en su cero, con el propósito explícito de divertir al lector y el implícito de apoyar sus ideas sobre Mateos. La historia trata de un perico que dice groserías frente a todo mundo, excepto ante su amo y ante Cero, pues cuando ve que cualquiera de los dos se acerca, canta "Santo Dios, Santo Fuerte, Santo inmortal". Con lo que se apoya la idea, como lo sugiere Díaz y de Ovando (xxxvi), de que los pericos saben lo que dicen o, por lo menos, saben ante quién sí y ante quién no decir algo.

Inmediatamente después, Riva Palacio aprovecha para insertar una cita de Herodoto y luego la "Primera versión de El buen ejemplo", donde se cuenta la historia de don Lucas, un maestro de escuela, y de su perico, el que un día, aprovechando una oportunidad, huye volando a la sierra cercana. Cuando tiempo después el profesor tiene que hacer un viaje y atravesar una buena parte del territorio por donde había huido su viejo amigo, se encuentra a éste aleccionando a una bandada de pericos, que repiten incansables " $b, a, n, b a n, b, e$, $\mathrm{n}$, ben". El cuento termina con un comentario que el perico le hace 
al profesor: "Don Lucas, ya tengo escuela" (Riva Los ceros 239). Nuevamente, como en la primera anécdota de pericos, se apoya la idea de que los pericos sí saben lo que dicen y que Mateos, no. De ahí el carácter probatorio de ambos textos.

Cabe una aclaración: si bien, quizá, el tono irónico de Cero evita que las ideas propuestas en el texto sean ejemplo de univocidad, es sólo mediante el reconocimiento de la ironía que el lector puede entender el sentido profundo de las frases de Cero, así como la función de apoyo a las ideas sugeridas por las mismas, mediante las dos anécdotas sobre pericos. También es claro que sólo después de entender esa función es que se puede dar con la propuesta de sentido de los dos cuentitos, sentido que está determinado por la semblanza sobre Mateos y las ideas que se plantean sobre él y su vida pública.

Debido al carácter probatorio de una idea por parte de las dos anécdotas, creo que ambas deben ser consideradas como exempla, pues como señala Rolando Carrasco, el exemplum se relaciona con la hipótesis planteada mediante la interpretación, "más o menos subjetiva", que el escritor hace del mismo, al considerarla como prueba de la afirmación, y tiene una "función catequética, como ilustración o “icono verbal"' (41). Además, no creo que sea gratuita su inserción al final, pues, según observa Juan José Prat Ferrer, desde el primer uso sistemático de los exempla por los cristianos con Gregorio Magno (540-604), algunos de éstos se insertaron al final del discurso (Prat 4). Además, Manuel Pérez señala que

En los discursos posteriores a las preceptivas humanistas, los fines de [la] conclusión operoratio, como en la antigüedad, eran refrescar la memoria, [respecto] tanto [...] a la causa del discurso como [...] a las diferentes razones o inducciones traídas para probarla; además, la conclusión servía para influir en los afectos del auditorio con el fin de disponerlo a una persuasión final, pues ésta viene a ser ya la última oportunidad para hacerlo. (107)

También hay que considerar que "a finales del siglo XIx [se llegó a considerar el exemplum] como una anécdota, un cuento entretenido, 
un relato verdadero o legendario" (Nieto 4) y que la apertura de los diarios a los cuentos, por esas mismas fechas y como señala Ignacio Díaz Ruiz, "ofrecen la oportunidad de ensayar, reflexionar y exponer ideas propias; permiten formular una visión del mundo y explayar la imaginación" (xv).

Aunque, como es de esperarse, los rasgos característicos del exemplum en Riva Palacio tienen más relación con autores de la Edad Media española (Juan Ruiz y don Juan Manuel), de la Colonia en la Nueva España (fray Diego Valadés) y con el relato ejemplar del XIX (Juan Valera y Leopoldo Alas), es imposible negarle, como abogado que era, por el uso probatorio de los cuentitos y por la gran cantidad de citas que incluye en el cero dedicado a Mateos, su conocimiento de retórica clásica y en específico de la retórica de Quintiliano, para quien el exemplum era "traer un hecho sucedido o cómo sucedió, útil para probar lo que queremos" (303).

Hay que advertir, sin embargo, que en el exemplum, este carácter probatorio de una afirmación previa, que es parte de una estructura discursiva mayor - un sermón o una semblanza, como es el caso del cero dedicado a Mateos-, se convertirá en la afirmación misma cuando se individualice; transformándose, como explica Cándano, en lo que respecta al exemplum medieval -pero que también creo aplicable en parte para el siglo XIX-, en un "recurso didáctico [...] utilizado para mostrar las debilidades individuales o los males comunes de la sociedad, de tal manera que el público se inclinara por hacer el bien; así como para patentizar, cuando hubiere lugar y con refinada perspicacia, diversas creencias" (24).

Según Cándano, las propiedades más importantes del exemplum,

son la brevedad [en la 'Primera versión de El buen ejemplo']; la fuerza didáctica y persuasiva [como he señalado de la versión final]; la unidad conceptual y/o narrativa entre uno y otro exemplum (si no en la totalidad del texto al menos por secciones) [muy presente en este caso]; el carácter de prueba o apoyo [también ya señalado]; la capacidad 'carismática'[perceptible a primera vista] y la univocidad interpretativa [lograda, paradójicamente, desde la ironía] (32) 
Cantos Casenave propone dos elementos más del exemplum, que creo básicos para entender la función de la "Primera versión de El buen ejemplo", "las protestas de veracidad [que se dan en el cuentito desde el inicio] y la configuración de los personajes como prototipos, sin un desarrollo psicológico [como don Lucas y el perico]" (30). Yo agregaría otro elemento: la importancia de que el exemplum tenga relación con una visión del mundo cercana al posible receptor, como puede entenderse el uso de los exempla americanos extraídos de la tradición oral local en el libro Rethorica Christiana, de fray Diego Valadés. De acuerdo con Díaz Ruiz, a finales del siglo XIX los cuentistas llevaron a sus últimas consecuencias esta fijación con el espacio tiempo de la enunciación, al escribir relatos "sugeridos por la fecha o algún acontecimiento próximo a su publicación, una nota policiaca o alguna otra referencia específica del momento" (xvii).

Según Carrasco, las distintas crónicas incluidas en la Rhetorica christiana son una especie de exempla históricos, lo que sugiere una toma de postura frente al indígena y la Iglesia europea y sus representantes: "Este elemento nos hace suponer que [además del ...] carácter didáctico-preceptivo de la obra -referido a una aplicación práctica de la oratoria sagrada-, en ella se hacen evidentes los signos de una estrategia de legitimación y defensa del nuevo orden espiritual americano" (43). Es decir, hay en los exempla de Valadés una doble función: 1. la más obvia de transmisión de los conocimientos retóricos, mediante el uso de exempla novohispanos; y 2. un intento por justificar una nueva forma de concebir el mundo, la americana. Pero me interesa, sobre todo, resaltar que es el énfasis en la realidad de los receptores lo que permite a estos últimos reconocerse fácilmente en los exempla. Muchos de ellos, extraídos, como se mencionó, de la tradición oral; un punto elemental para entender la poética de Riva Palacio, en el que no profundizaré en estas notas.

Respecto de la intención probatoria, existen, como ya mencioné, dos funciones que la "Primera versión de El buen ejemplo" tiene: Una primera explícita, que es divertir a los lectores, como lo sugiere Cero: "Yo me atrevo a decir semejante cosa, porque he tenido oportunidad de hacer algunas observaciones, que si aquí no vienen al 
caso, no por eso dejarán de divertir a los lectores" (Los ceros 237). Y una segunda función implícita que respalda la afirmación de Riva Palacio de que los pericos, al contrario de "los hombres ligeros para expresarse", sí "conocen el peso y la significación de sus palabras" (Los ceros 237). Esta última sólo es perceptible al comparar la visión propuesta sobre Mateos, en el cero, con la supuesta capacidad de los pericos para entender lo que dicen, en el cuento. Además, está el comentario final de Riva Palacio donde señala que quiso hacer una "fabulilla" del cuento, el título que le pone a la última versión, "El buen ejemplo" -que resalta la ejemplaridad del texto-, y el cierre del cuento a manera de moraleja irónica: "Yo he tenido ganas de hacer de este cuento una fabulilla, y la moraleja, que por supuesto debe ser en verso, ha de decir: 'Dios nos tenga de su mano, el día en que muchos de nuestros literatos abran escuela"' (Los ceros 239). En contraste, sin embargo, aparece el cierre del cuento en su versión definitiva, que dice, también de manera irónica: "Desde esa época los loros de aquella comarca, adelantándose a su siglo, han visto disiparse las sombras del obscurantismo y la ignorancia" (Cuentos del general 93). Y esto amplía, desde luego, el rango de la crítica de Mateos a todo un sistema educativo, el de la educación memorística, centrada en la repetición; pues, como menciona el narrador de la última versión, este método se usaba, en la época en que don Lucas daba clases, para enseñar las letras, las sílabas, la doctrina cristiana y las tablas de multiplicar:

En esa escuela, siguiendo tradicionales costumbres y uso general en aquellos tiempos, el estudio para los muchachos era una especie de orfeón, y en diferentes tonos, pero siempre con desesperante monotonía, en coro se estudiaban y en coro se cantaban lo mismo las letras y las sílabas que la doctrina cristiana o la tabla de multiplicar. (Cuentos del general 86)

Lo que daría como resultado, si nos quedáramos en esa lógica, que ni los alumnos pericos de la escuela de Perico ni los alumnos humanos de la escuela de don Lucas, sujetos a la enseñanza memorística, entendieron o supieron jamás lo que decían; justo como 
Juan Antonio Mateos. Es decir, al individualizarse el texto, la crítica se generaliza y pasa de la figura de Mateos, quien ha desaparecido, a la figura del Estado, el encargado de velar por que el sistema educativo sea el adecuado.

Respecto a las protestas de veracidad como elemento del exemplum, éstas se dan desde el inicio del cuento y a partir del juego propuesto por la ironía. Por ejemplo en la primera versión se lee: "Y así voy a referir una historia que de testigos veraces, aunque no les creí, supe en una de las poblaciones del Sur de la República" (Los Ceros 238-239). En tanto que en la versión definitiva se menciona:

Si yo afirmara que he visto lo que voy a referir, no faltaría, sin duda, persona que dijese que eso no era verdad; y tendría razón, que no lo vi, pero lo creo, porque me lo contó una señora anciana, refiriéndose a personas a quienes daba mucho crédito y que decía haberlo oído de quien llevaba amistad con un testigo fidedigno, y sobre tales bases de certidumbre bien puede darse fe a la siguiente narración. (Cuentos del general 85)

Como se observa, en la primera versión parece resaltarse el aspecto ficcional del texto, para contrastarlo con la configuración de un Mateos parlanchín, incoherente y desorganizado; particularidades del personaje sugeridas en la semblanza, que por su poder para subordinar la anécdota, se considerarían reales o, por lo menos, aplicables al aludido. En la última versión, aunque se pone en duda la veracidad de los testigos que lo contaron, hay, por parte del narrador, un intento por establecer un pacto con el lector, respaldando con su credibilidad lo narrado, pues el narrador dice creer lo que le contaron. Aquí ya no se resalta lo ficcional, porque ya no es necesario contrastar la historia del perico con ninguna semblanza. Es decir, a diferencia de la primera, la segunda versión no está subordinada a ningún otro texto, aunque haya dependido de él en sus orígenes.

Para terminar con estas notas, baste comentar que con mi intención de integrar la "Primera versión de El buen ejemplo" a la tradición del exemplum busco aportar elementos para la reconsideración del didactismo de Cuentos del general. A pesar de la estructura miscelá- 
nea del libro, creo que es perceptible cierto tipo de unidad en la función que cumple cada texto. Es decir, al contrario de lo que se ha sugerido por muchos de los estudiosos del cuentario, la unidad de éste, perceptible a partir del título del libro, no está en su temática sino en su función, en lo que busca generar en el lector, una especie de reflexión, que lo lleve a revisar las distintas motivaciones que un individuo puede tener para actuar de determinada manera.

\section{Bibliografía}

Cándano Fierro, Graciela. Estructura, desarrollo y función de las colecciones de exempla en la España del siglo XIII. México: Universidad Nacional Autónoma de México, 2000.

Carrasco M., Rolando. "El exemplum como estrategia persuasiva en la Rhetorica christiana (1579) de fray Diego Valadés". Anales de Instituto de Investigaciones Estética 22. 77. (2000): 33-66.

Díaz Ruiz, Ignacio. "Introducción". El cuento mexicano en el modernismo (Antología). México: Universidad Nacional Autónoma de México, 2006, ix-xxxv.

Díaz y de Ovando, Clementina. "Prólogo". Vicente Riva Palacio, Cuentos del general. México: Porrúa, 1971, vii-xlvii.

Nieto, María Dolores. Estructura y función de los relatos medievales. Madrid: Consejo Superior de Investigaciones Científicas, 1993.

Pérez Martínez, Ramón Manuel. Historias y cuentos para la reforma de costumbres en Nueva España: retórica del ejemplo en Luz de verdades catholicas [...] (1692-1699) de Juan Martinez de la Parra, S.J. Tesis de doctorado. México: El Colegio de México, 2008.

Prat Ferrer, Juan José. "Los exempla medievales: una etapa escrita entre dos oralidades". Oppidum 3. (2007): 165-188.

Quintiliano, M. Fabio. Instituciones oratorias. Tr. El P. de las Escuelas Pías. Madrid: Real Arbitrio de Beneficencia, 1799.

Riva Palacio, Vicente [Cero]. Los ceros. Galería de contemporáneos. México: F. Díaz de León, 1882.

- Cuentos del general. Madrid: Sucesores de Rivadeneyra, 1896. 